\title{
Value of assessing post prandial blood glucose as a surrogate for fasting blood glucose in an outpatient medical clinic: a descriptive study
}

\section{TP Weerarathna ${ }^{1}$, AS Dissanayake ${ }^{2}$}

${ }^{1}$ Senior Lecturer in Medicine, ${ }^{2}$ Lecturer in Medicine, Faculty of Medicine, University of Ruhuna, Galle.

\begin{abstract}
Objectives: To assess the value of estimation of postprandial blood sugar (PPBS) as a surrogate for fasting blood glucose (FBS) and to estimate the prevalence and profile of patients with diabetes with normal fasting blood sugar and elevated postprandial blood sugar (Isolated postprandial hyperglycaemia).
\end{abstract}

Setting: Diabetic patients attending an outpatient medical clinic.
Methods: In 60 consecutive patients with diabetes attending an out-patient medical clinic, capillary blood glucose estimations were carried out in the fasting state (at least after 8 hours of fasting) and postprandial state (two hours after lunch) on the same day. Data on age, sex, and duration of diabetes, weight and type of oral hypoglycaemic therapy were also collected.

Results: 47 out of 60 patients studied had both FBS and PPBS moving in the same direction (either normal FBS and PPBS or elevated FBS 
and PPBS on the same day). Only 8 patients had elevation of postprandial glucose level in the presence of normal FBS. Patients with long duration of diabetes and who are taking multiple oral hypoglycaemic therapies were more likely to show this phenomenon.

Conclusion: Estimation of PPBS is reliable as a surrogate for FBS in 4 out of 5 patients with diabetes. Considering the convenience to some patients who find it difficult to undergo fasting, PPBS is a reliable alternative for FBS, especially in the absence of a gold standard test of glycaemic control such as glycosylated haemoglobin estimations.

\section{Introduction}

A number of major prospective randomised studies have shown that tight control of blood glucose is an essential requirement in the prevention or delaying the onset of macro vascular and micro vascular complications of both type 1 and type 2 diabetes mellitus [1, 2]. Control of blood glucose in patients with diabetes can be assessed by several methods [3]. These include assessment of glycosylated hemoglobin (HBA1C), fasting blood sugar (FBS), and postprandial blood sugar (PPBS). The gold standard for assessment of glycaemic control at follow up is the glycosylated haemoglobin level [4]. This test is not available in the state health sector. It costs Rs. 600.00 in a private laboratory. This figure is beyond the reach of most patients attending clinics at state hospitals.

Despite paucity of evidence for its usefulness, fasting blood sugar values are used to assess glycaemic control in the absence of the ideal in most Sri Lankan hospitals and out patient clinics. However, this test is inconvenient to a patient with diabetes attending to an out-patient clinic for follow-up. They have to remain fasting overnight till they get to a laboratory to give the blood sample for testing. Those who come from long distances, the frail and the elderly patients find this a difficult task. On the contrary, two hour post prandial blood glucose (PPBS) assessments cause much less disruption of daily activities of the diabetic patient. When the blood glucose assessment is carried out with capillary blood glucose using a glucometer, the patient can undergo blood glucose testing just prior to their consultation with the doctor.

\section{Objectives}

1. To assess the value of the postprandial blood sugar as a surrogate for the fasting blood glucose estimation.

2. To estimate the prevalence rate and the patient profile of patients with diabetes with normal fasting blood sugar and elevated post prandial blood sugar levels.

\section{Methods}

This was a descriptive study. Sixty patients with type 2 diabetes mellitus attending the University Medical Clinic at the Teaching Hospital Karapitiya were assessed. Data on age, sex, body mass index, type of oral hypoglycaemic agents, self reported dietary and drug compliance were collected. Capillary blood glucose measurements of all participants were done in the fasting state (at least eight hours of fasting) as well as in the postprandial state, two hours after lunch, the same day. Acceptable control level of blood glucose were defined as FBS value equal or less than 120 $\mathrm{mg} / \mathrm{dL}$ and PPBS value equal or less than 160 $\mathrm{mg} / \mathrm{dL}$. Isolated post prandial hyperglycaemia was defined as FBS equal or less than $120 \mathrm{mg} / \mathrm{dL}$ with PPBS equal or more than $160 \mathrm{mg} / \mathrm{dL}$.

\section{Results}

Baseline characteristics of the study sample are as follows.

\begin{tabular}{|l|l|}
\hline Characteristic & Value \\
\hline Number of patients & 60 \\
\hline Mean age & 59.2 years \\
\hline Male : Female ratio & $1: 3$ \\
\hline Mean duration of diabetes & 5.3 years \\
\hline Mean BMI & $22 \mathrm{~kg} / \mathrm{m}^{2}$ \\
\hline Treatment & \\
Diet control only & $10 \%$ \\
Sulphonylurea only & $25 \%$ \\
Metformin only & $24 \%$ \\
Sulphonylurea and Metformin & $41 \%$ \\
\hline
\end{tabular}


Fasting and Postprandial blood glucose values.

\begin{tabular}{|l|c|c|}
\hline & $\begin{array}{c}\text { PPBS }<160 \\
\mathrm{mg} / \mathrm{dL}\end{array}$ & $\begin{array}{c}\text { POBS }>160 \\
\mathrm{mg} / \mathrm{dL}\end{array}$ \\
\hline FBS $<120 \mathrm{mg} / \mathrm{dL}$ & 34 & 08 \\
FBS $>120 \mathrm{mg} / \mathrm{dL}$ & 05 & 13 \\
\hline
\end{tabular}

The sensitivity of elevated PPBS in detecting the patients with elevated FBS was $72 \%$ with a specificity of $80 \%$. The positive predictive value of elevated PPBS was $62 \%$ and the negative predictive value of normal PPBS was $87 \%$.

The prevalence rate of isolated postprandial hyperglycaemia was $15 \%$.

Characteristics of patients with postprandial hyperglycaemia.

\begin{tabular}{|l|l|l|}
\hline Characteristic & $\begin{array}{l}\text { FBS }<\mathbf{1 2 0} \\
\text { and } \\
\text { PPBS>160 } \\
\text { (mg/dL) }\end{array}$ & $\begin{array}{l}\text { Other } \\
\text { patients }\end{array}$ \\
\hline Number of patients & 08 & 52 \\
\hline Mean age & 53.7 years & 60.1 \\
\hline Duration of diabetes & 7.1 years & 5.1 years \\
\hline Mean BMI & $25.4 \%$ & $24.3 \%$ \\
\hline Treatment & $12.5 \%$ & $3.8 \%$ \\
Diet control & $12.5 \%$ & $26.8 \%$ \\
Sulphonylurea & $12.5 \%$ & $28.8 \%$ \\
Metformin & $62.5 \%$ & $38.5 \%$ \\
Sulphonylurea and \\
$\quad$ Metformin
\end{tabular}

\section{Discussion}

In the study sample of 60 patients with type 2 diabetes, 34 patients had both FBS and PPBS within the normal limits (less than $120 \mathrm{mg} / \mathrm{dL}$ and $160 \mathrm{mg} / \mathrm{dL}$ respectively). Only 13 patients had both elevated FBS and PPBS. Altogether in 47 patients both FBS and PPBS moved in the same direction. That is 4 out of 5 patients undergoing follow up at the out patient clinic is likely to have his/her PPBS reflecting accurately the normo or hyperglycaemia of the FBS value.
The sensitivity and specificity of the use of elevated PPBS levels as a surrogate for FBS was more than $70 \%$. The positive and negative predictive values were also acceptably high (62\% and $87 \%$ respectively). The costs of the tests are similar. Considering the enhanced patient convenience and its special suitability to some categories of patients, we suggest that PPBS is a satisfactory alternative to FBS to assess overall glucose control in an out patient medical clinic.

Only 8 patients showed elevation of their PPBS in the presence of a normal FBS. Therefore isolated postprandial hyperglycaemia was found only among 08 out of 60 patients (13\%).

There is some evidence that elevation of postprandial glucose is an important predictor of macro vascular disease in individuals with diabetes [5]. Use of special dietary and pharmacological interventions has been suggested normalize postprandial blood glucose in this category of patients with diabetes. Some of the newer oral hypoglycaemic agents with a dominant effect on the postprandial state (prandial glucose regulators) such as Acarbose are thought to be particularly useful for these patients [6]. The study data reveals that isolated elevated PPBS is more prevalent among patients with longer duration of diabetes and those on multiple oral hypoglycaemic therapies.

The results of the study indicate that in a resource poor setting with no access to glycosylated haemoglobin for assessment of glycaemic control, assessment of PPBS alone offers a convenient and a reliable alternative to the FBS. It obviates the need for fasting, which can be problematic in some elderly patients and waste of a few hours on the day of the clinic visit. Assessment of PPBS can easily be carried out at the out patient diabetes clinic itself using capillary blood with a glucometer. Assessment of PPBS and FBS in the same patient on the same day in the category of diabetic patients with a longer duration of the disease and those on multiple oral hypoglycaemic therapy would also enable identification of patients with isolated postprandial hyperglycaemia who would benefit from a special therapeutic approach. 


\begin{tabular}{|c|c|c|c|}
\hline \multicolumn{4}{|l|}{ Calculations } \\
\hline Sensitivity & $\mathrm{TP} / \mathrm{TP}+\mathrm{FN}$ & $13 / 13+05$ & $72 \%$ \\
\hline Specificity & TN/TN+FP & $34 / 34+08$ & $80 \%$ \\
\hline $\begin{array}{c}\text { Positive predictive } \\
\text { value }\end{array}$ & $\mathrm{TP} / \mathrm{TP}+\mathrm{FP}$ & $13 / 13+08$ & $62 \%$ \\
\hline NPV & $\mathrm{TN} / \mathrm{TN}+\mathrm{FN}$ & $34 / 34+05$ & $87 \%$ \\
\hline
\end{tabular}

\section{References}

1. The Diabetes Control and Complications Trial Group: The effect of intensive treatment of diabetes on the development and progression of long term complications in insulin dependant diabetes mellitus. New England Journal of Medicine 1993; 329: 977-86.

2. UK Prospective Diabetes Study Group: Intensive blood glucose control with sulphonylureas or insulin compared with conventional treatment and risk of macro vascular and micro vascular complications in patients with type 2 diabetes. Lancet 1998; 352: 83753.
3. Goldstein DE, Little RR, Lorenz RA, Malone JI, Nathan D, Peterson D: Tests of Glycaemia in diabetes (Technical Review) Diabetes Care 1995; 18: 896-909.

4. Rholfing CL, Weidmyer HM, Little RR, England JD, Tennil A, Goldstein DE: Defining the relationship between plasma glucose and HBA1C Analysis Diabetes Care 2002; 25: 275-8.

5. Temelkowa-Kurtschiev TS, Koehler C, Henkel D, Leonhardt W, Fuecker K, Hanefeld M: Post Challenge plasma glucose and glycaemic spikes are more strongly associated with atherosclerosis than fasting glucose or HBA1C level. Diabetes Care 2000; 23: 1830-4.

6. Lebovitz HE. Alpha-glucosidase inhibitors as agents in the treatment of diabetes. Diabetes Reviews 1998; 6: $132-45$. 